\title{
EFFECT OF LOCATION OF SHEAR WALL ON PERFORMANCE OF BUILDING FRAME SUBJECTED TO LATERAL LOAD
}

\author{
Vaishali G Ghorpade ${ }^{1}$, H. Sudarsana Rao ${ }^{2}$, O.Ravi $^{3}$ \\ 1.Professor, Department of Civil Engineering, JNTU College of Engineering, \\ Ananthapuramu, Andhra Pradesh, India, \\ ghorpade_vaishali@yahoo.co.in \\ 2.Professor, Department of Civil Engineering, JNTU College of Engineering, \\ Ananthapuramu, Andhra Pradesh, India, \\ hanchate123@yahoo.co.in \\ 3.PG student, Department of Civil Engineering, JNTU college of Engineering, \\ Ananthapuramu, Andhra Pradesh, India, \\ oburaviyadav@gmail.com
}

\begin{abstract}
The practice before 1960s has been to plan structures principally for gravity loads and check the sufficiency of the structure for security against sidelong loads. It is set up that the plan of a multi-story building is administered by horizontal burdens and it ought to be the prime worry of creator to give sufficient security to structure against parallel burdens. Many existing RC outline structures situated in seismic zones are insufficient to withstand tremors. Lacking sidelong resistances and poor enumerating of support are the fundamental explanations behind deficient seismic execution. Shear divider framework is a standout amongst the most normally utilized sidelong load opposing system for tall structures. Shear dividers have high in-plane quality and firmness, which can be utilized all the while for opposing substantial even and gravity loads. In tall structures, it is critical to guarantee sufficient horizontal solidness to oppose sidelong load.
\end{abstract}

The point of this work is to know the conduct of RCC edge without and with shear divider in successful situating in casing. For this reason one casing is considered without shear divider and other casing with shear divider at position-1, position-2 and position-3 of eight storeyed building has been considered. Models are contemplated in all the four zones for contrasting sidelong uprooting and load exchange with different auxiliary components with various situating of shear divider. Tremor load is ascertained according to May be: 1893-2002 (Part-1), the reaction decrease figure, significance consider, zone variable are taken from IS: 1893-2002 (Part-1) and are connected to a building situated in Zone II, Zone III, Zone IV and Zone V. The structures are demonstrated utilizing programming ETAB Nonlinear $v$ 9.7.2

Giving shear dividers at sufficient areas significantly decreases the relocations because of quake. Henceforth bookkeeping shear divider in a building will shape an effective horizontal drive opposing framework. The outcomes show better imperviousness to parallel load within the sight of shear divider situating in position- 3 in an edge

Key Words: Framed buildings, thin wide column, Analysis, Time period, Base shear, Conventional RC Frame, pushover analysis

\section{INTRODUCTION}

Shear divider are one of the phenomenal methods for giving seismic tremor imperviousness to multi storeyed strengthened solid building. The structure is as yet harmed because of a few or the other reason amid seismic tremors. Conduct of structure amid seismic tremor movement relies on upon dissemination of weight, firmness and quality in both even and planes of building. To lessen the impact of tremor fortified solid shear dividers are utilized as a part of the building. These can be utilized for enhancing seismic reaction of structures. Auxiliary plan of structures for seismic stacking is principally worried with basic security amid significant Earthquakes, in tall structures, it is vital to guarantee satisfactory sidelong solidness to oppose parallel load. The arrangement of shear divider in working to accomplish unbending nature has been discovered successful and practical. At the point when structures are tall, bar, section sizes are very overwhelming and Reinforcement steel required is expansive. So there is part of clog at shaft segment joint and it is hard to put and vibrate concrete at this place and uprooting is very overwhelming. Shear dividers are generally utilized as a part of tall working to keep away from fall of structures. At the point when shear dividers are arranged in beneficial positions in the building, they 
can frame a proficient horizontal constrain opposing framework. The real criteria now-a-days in planning RCC structures in seismic zones is control of parallel relocation coming about because of sidelong strengths. In this work exertion has been made to research the viable of Shear Wall position on parallel relocation and Base Shear in RCC Frames. Four sorts of structures, G+7 are considered with one of the casings were furnished with plan of shear divider in the position at lift dividers.

Non-direct static investigation (sucker examination) was completed for four sorts of casings and the edges were then contrasted and the push over bends. Dislodging and Base shear is computed from the bends and analysed. The nonlinear investigation of an edge has turned into an essential instrument for the investigation of the solid conduct including its heap redirection example and breaks design. It helps in the investigation of different qualities of solid part under various load conditions.

\section{LITERATURE REVIEW}

Karim Tarbali et al., (2014)It portray a solitary run weakling technique to survey the seismic reaction of lopsided arrangement structures when subjected to unidirectional tremor ground movements. The impact of the higher and torsional modes is consolidated into single-run invariant load design. The heap example is determined in view of the tallness insightful circulation of the modular story shear and torsional minute in stories of the structure. Keeping in mind the end goal to consider the prompt changes in powerful qualities of the structure in the nonlinear stage, limit bend of the structure is gotten in view of the momentary twisted state of the structure, utilizing the versatile limit range strategy (ACSM). This proposed technique (i.e., ST-ACS) is a solitary run strategy which encourages following the nonlinear reaction of the structure amid the sucker examination. Two awry arrangement steel minute opposing edges with 9 and 20 stories have been utilized to assess the exactness of the proposed system against the outcomes from nonlinear reaction history examinations. Comes about because of numerical examinations show fitting exactness of the proposed system in catching the relative removal of structures when contrasted with the outcomes from nonlinear reaction history investigations[1].

Kazem Shakeri et al., (2010)Proposed another supportive weakling technique i.e., story shear-based versatile sucker strategy called "SSAP" in view of the story shears which considers the inversion of sign in the higher modes. In each progression, the connected load example is gotten from the momentary consolidated model story shear profile. The indication of the connected loads in back to back steps are changed and the structure is all the while pushed and pulled in various story levels. Another part of the proposed technique is that at each progression an expected central mode shape is gotten from the heap profile. In light of this versatile basic mode shape and the vitality idea, the multi level of flexibility framework is changed over into single level of opportunity framework. The outcomes demonstrate a honorable precision in forecast of pinnacle inelastic float reaction, particularly where the impacts of higher modes are imperative. A mix of this technique with the ordinary sucker approach, called "SS-MI" brings about more exact estimation of pinnacle inelastic float in all story levels contrasted with the other weakling approaches[2].

Shaik Kamal Mohammed Azam., 2013Displayed a review on seismic execution assessment of multi-storeyed RC surrounded structures with shear divider.[3] A correlation of auxiliary conduct as far as quality, solidness and damping attributes is finished. The arrangement of shear divider has huge impact on sidelong quality in taller structures while it has less impact on parallel solidness in taller structures. The arrangement of shear divider has critical impact on horizontal firmness in structures of shorter tallness while it has less impact on sidelong quality. The impact of shear dividers is huge as far as the damping qualities and period at the execution point for tall structures. Arrangement of shear dividers symmetrically in the furthest minute opposing edges and ideally interconnected in commonly opposite bearing framing the center will have better seismic execution as far as quality and firmness.

Misam Abidi, Mangulkar Madhuri. N;2012Displayed an evaluation to comprehend the conduct of Reinforced Concrete surrounded structures by sucker examination and the Comparative review was accomplished for various models regarding base shear, relocation, execution point. [4]The inelastic conduct of the case structures are analyzed via completing uprooting controlled sucker investigation. Utilizing shear dividers to the structures in various game plan with a specific end goal to lessen delicate story impact on basic seismic reaction.

Y.M.Fahjan et al 2010In the nonlinear examinations, the nonlinear material model of mid-dock casing is for the most part in view of plastic pivot idea situated on the plastic zones toward the finish of the auxiliary components or circulated along the part traverse length. The nonlinear conduct of the shell components is by and large demonstrated utilizing multi-layer shell component with layered material model. The shear divider with two layers of longitudinal and transverse fortification bars could be displayed with various methods to represent the RC material nonlinearity. [5]In this examination diverse methodologies for direct and nonlinear demonstrating of the shear dividers in basic investigations of structures are considered and connected to RC working with shear dividers 
Anil K. Chopra, et al.,(2004)Augmented the model sucker examination (MPA) system to unsymmetricarrangement structures. In the MPA method, the seismic request because of individual terms With invariant constrain dissemination now regular in auxiliary building rehearse. The MPA gauge of seismic request because of an extraordinary ground movement (counting a forward directivity beat) has been appeared to be for the most part exact for unsymmetric frameworks to a comparable degree as it was for a symmetric building. The MPA technique considering a gathering of ground movements and recording the inclination and scattering in the strategy connected to unsymmetric structures, as has been expert for symmetric structures[6]

\section{OBJECTIVES}

To concentrate the execution of RC plane edges under horizontal burdens (Earthquake loads).

To concentrate the inelastic reaction of RC plane casings utilizing Pushover analysis.।

To concentrate the varieties of sucker bend for a plane surrounded structure and for an encircled structure with shear dividers in different situating of edge.

\section{SCOPE OF STUDY:}

The present review is centered around the conduct of RCC edge for successful position of shear divider in the edge because of the sidelong stacking. This review will draw out the conduct of edge with and without shear divider in different positions in a multi storied structure.

The study is limited to the following scopes:

Only reinforced concrete framed structures are considered.

The frame considered is a 5 x 2 bays with 8 storeyed as height constant.

The dimension of shear wall is same as in various selected positions of frame

\section{METHODLOGY:}

For this purpose of study a plan of G+7 floor levels was considered. Forpush over study, RC plane frames with and without shear wall were analyzed and designed for gravity loads as per IS 456:2000 and lateral loads (earthquake loads) as per IS 1893 (part-1):2002.

For this review, 8-story working with a 3-meters stature for every story, normal in plan is displayed. The structures are thought to be settled at the base. The areas of auxiliary components are square and rectangular and story statures of structures are thought to be consistent including the ground story. The structures are displayed by utilizing programming ETAB Nonlinear v 9.7.2. Four unique models were contemplated with various situating of shear divider in building and models are considered in all zones looking at parallel dislodging for all models.

Model-1 RCC Frame without shear wall. (see Fig-1)

Model-2 RCC Frame with shear wall in Position-1. (see Fig-2)

Model-3 RCC Frame with shear wall in Position-2. (see Fig-3)

Model-4 RCC Frame with shear wall in Position-3. (see Fig-4)

\section{STRUCTURAL MODELLING}

For this review, 8-story working with a 3-meters stature for every story, consistent in plan is displayed. These structures were composed in consistence to the Indian Code of Practice for Seismic Resistant Design of Buildings[7]. The structures are thought to be settled at the base. The segments of basic components are square and rectangular. Story statures of structures are thought to be steady including the ground story. The structures are displayed utilizing programming ETAB Nonlinear v 9.7.2.

Four different models were studied with different positioning of shear wall in building. Models are studied in all four zones comparing lateral displacement for all models[8]

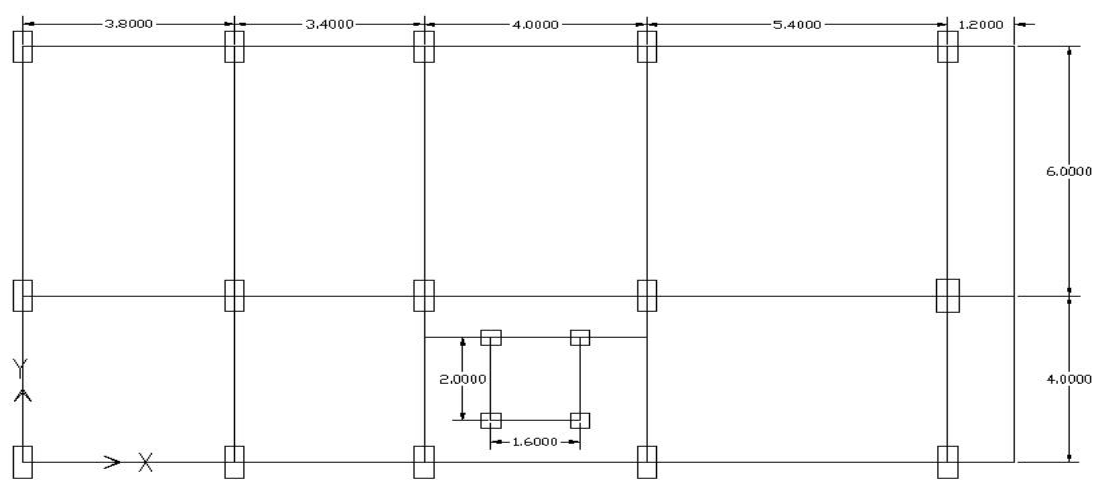

Fig.1 Model-1 Plan without Shear Wall 


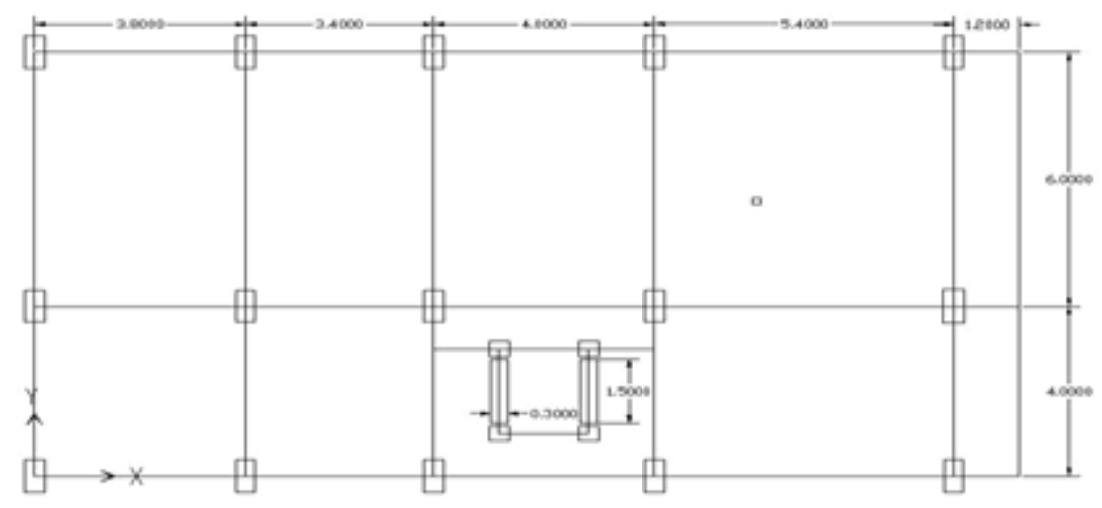

Fig.2 Model-2 Plan with Shear Wall Position-1

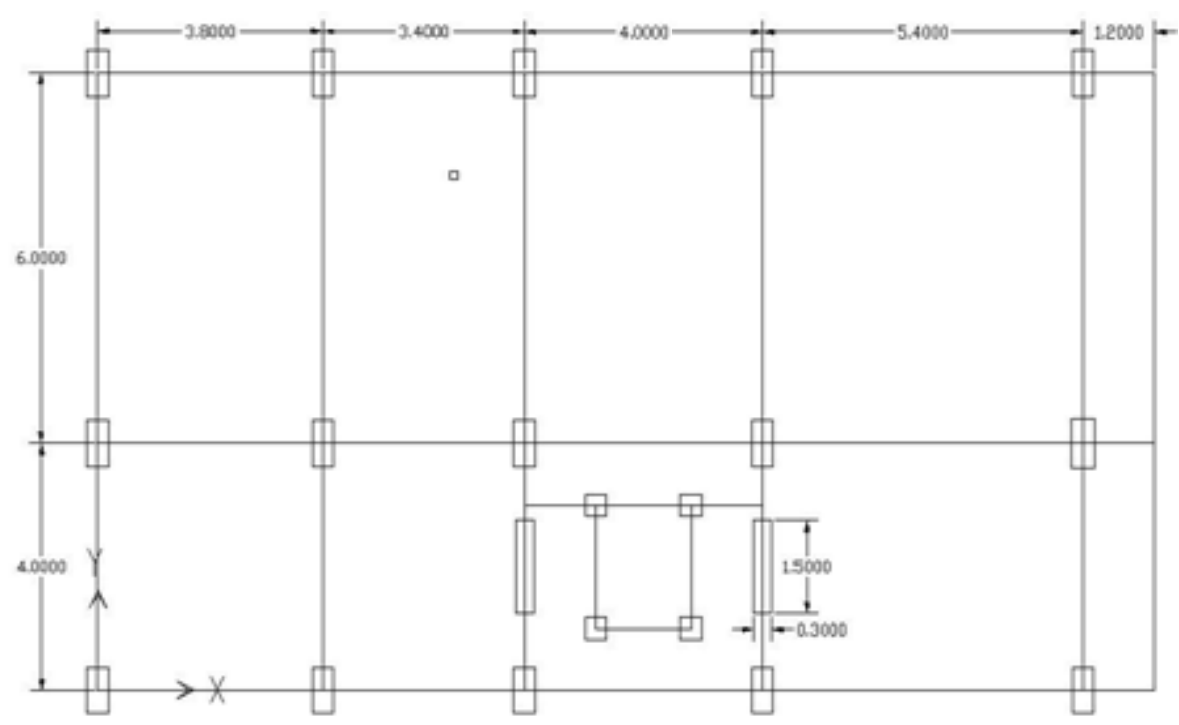

Fig.3 Model-3 Plan with Shear Wall Position-2

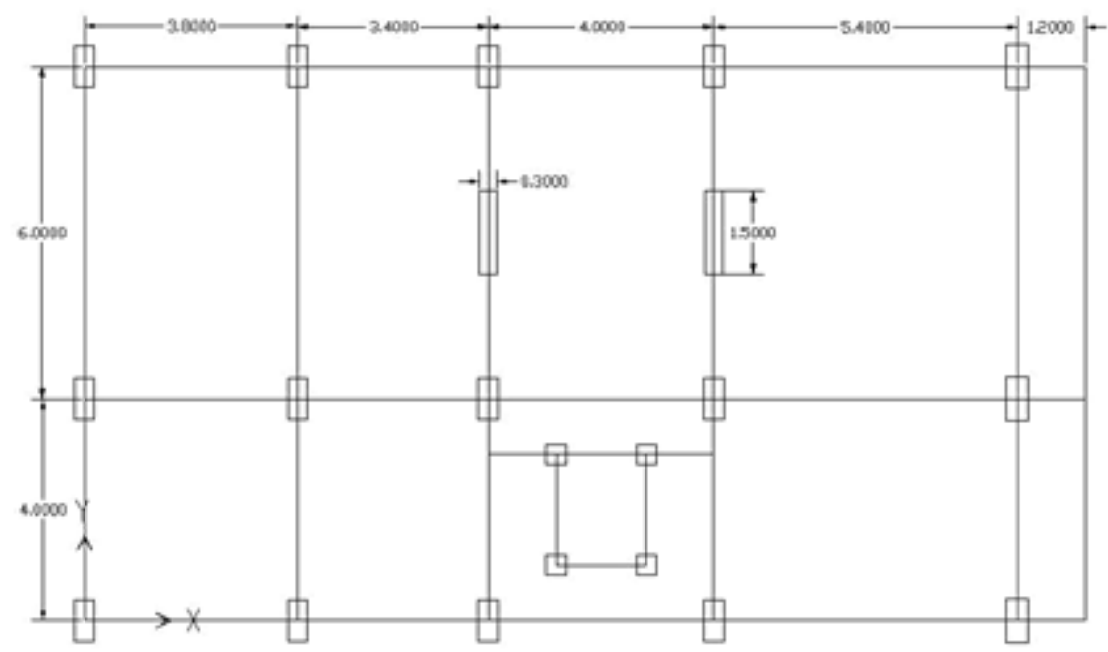

Fig.4 Model-4 Plan with Shear Wall Position-3

An eight story edge was demonstrated into E-Tabs without shear divider. Alongside the above casing, another three edge with shear dividers in various position was displayed in E-Tabs. The primary point is to determine the distinction in relocation and Base Shear between these four casings[9-12]

MEMBER PROPERTIES:

All the beams in the frame were sized to $0.3 \mathrm{~m} \mathrm{X} 0.45 \mathrm{~m}$.

All the columns in the frame were sized to $0.35 \mathrm{~m} \mathrm{X} 0.75 \mathrm{~m}$

The slab of $0.12 \mathrm{~m}$ thickness was taken for the analysis purpose and assigned to each floor. 
Default M3hinge was assigned to beams.

Default P-M-M hinge was assigned to columns.

MEMBER LOADING:

All the members were assigned the following loadings.

Self-Weight

External Wall Load--- $6 \mathrm{KN} / \mathrm{m}$

Internal Wall Load--- 5KN/m

Live Load-- 2 KN/m

Earth Quake Loading--as per IS- code:1983-2002

It was assumed that the wind force was not governing the frame efficiency.

\section{PUSH OVER CASES}

Two pushover cases were defined for the analysis.

Push-1 also known as Gravity push which is done for gravity loading ( DL+LL) for which it is done in load defined pattern.

Push-2 also known as lateral push in which the governing load is lateral load (EQ) for which it is done in displacement defined pattern.

\section{RESULTS}

- The outcomes from the investigation are the avoided shape and the arrangement of pivots with expanding load and their execution levels.

- $\quad$ The principle distinction between the edges can be found from the dislodging and base response plots i.e., push-over bends. Limit Spectrum bends can be drawn from the examined plot.

- From the limit range bend the presence of execution point can be noted. On the off chance that the execution point doesn't exist, the structure neglects to accomplish the objective execution level.

- Pushover curve have been developed for multi-storey frame with and without shea

- CASE-1: Multi Storey Frame without Shear Wall.

- CASE-2: The shear wall have been located in position case-1 at lift corners

- CASE-3: The shear wall have been located in position case-2 at beside lift as considering mid position of span length $4 \mathrm{~m}$.

- CASE-4: The shear wall been ocated in Position case -3 at longer span as mid position of span length 6m.

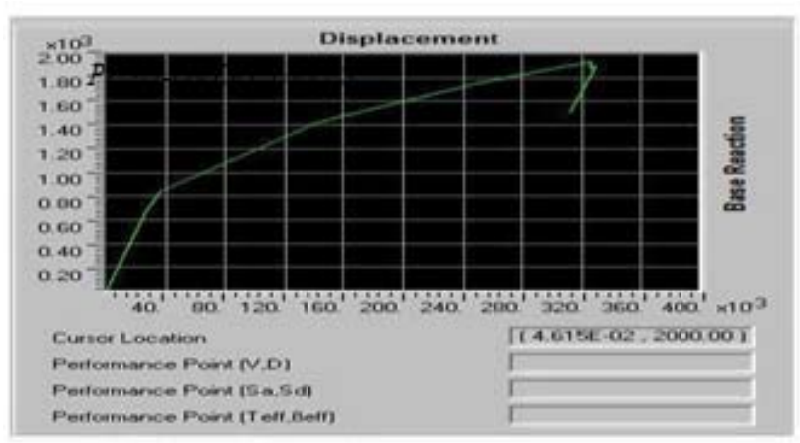

Fig.5 RCC frame Pushover curve without shearwall-

$$
\text { Lateral push }
$$

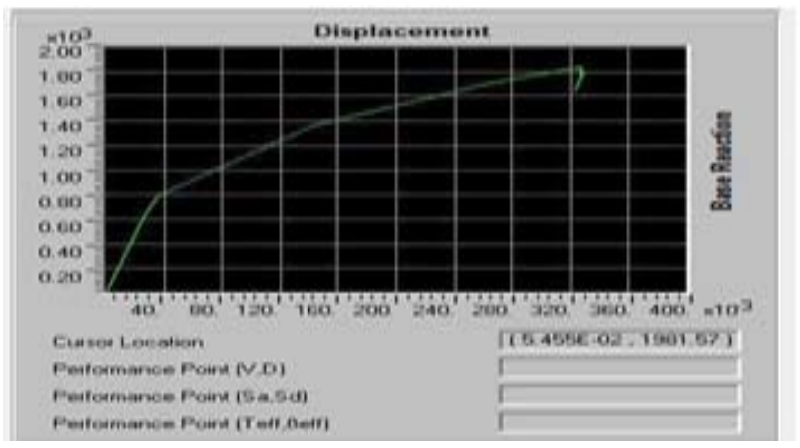

Fig.7 RCC frame Pushover curve with shearwall(position 2) LATERAL PUSH

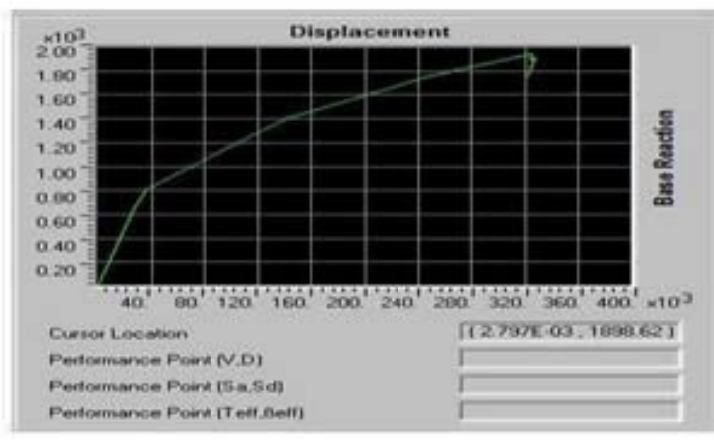

Fig.6 RCC Frame with pushover curve with shear wall (position1) lateral push

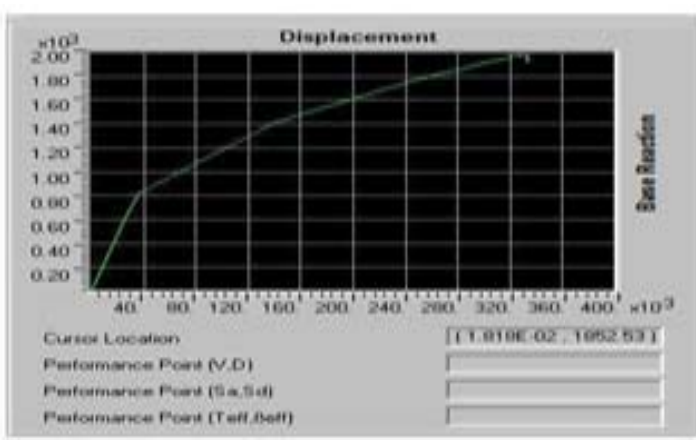

Fig.8 RCC Frame with pushover curve with shear wall (position 3) LATERALPUSH 
STATIC LINEAR ANALYSIS OF FRAME (MODEL-1)

TABLE 1 MODEL-1 WITHOUT SHEAR WALL FRAME

\begin{tabular}{|c|c|}
\hline 8 STOREY & (MODEL-1) DISPLACEMENT (mm ) \\
\hline Zone-2 & 130.24 \\
\hline Zone-3 & 203.11 \\
\hline Zone-4 & 301.37 \\
\hline Zone-5 & 442.68 \\
\hline
\end{tabular}

TABLE 2 COMPARING DISPLACEMENTS BETWEEN MODEL-1 AND MODEL-2

\begin{tabular}{|c|c|c|c|}
\hline 8 STOREY & $\begin{array}{c}\text { (MODEL-1) } \\
\text { DISPLACEMENT }(\mathrm{mm})\end{array}$ & $\begin{array}{c}\text { (MODEL-2) } \\
\text { DISPLACEMENT }(\mathrm{mm})\end{array}$ & $\begin{array}{c}\text { \% reduction in } \\
\text { Displacement }\end{array}$ \\
\hline Zone-2 & 130.24 & 119.13 & 8.5 \\
\hline Zone-3 & 203.11 & 184.5 & 9.1 \\
\hline Zone-4 & 301.37 & 272.65 & 9.5 \\
\hline Zone-5 & 442.68 & 399.55 & 9.7 \\
\hline
\end{tabular}

TABLE 3 COMPARING DISPLACEMENT BETWEEN MODEL-1 AND MODEL-3

\begin{tabular}{|c|c|c|c|}
\hline 8 STOREY & $\begin{array}{c}\text { (MODEL-1) } \\
\text { DISPLACEMENT (mm ) }\end{array}$ & $\begin{array}{c}\text { (MODEL-3) } \\
\text { DISPLACEMENT (mm ) }\end{array}$ & $\begin{array}{c}\text { \% reduction in } \\
\text { Displacement }\end{array}$ \\
\hline Zone-2 & 130.24 & 107.36 & 17.5 \\
\hline Zone-3 & 203.11 & 166.24 & 18.1 \\
\hline Zone-4 & 301.37 & 254.65 & 15.5 \\
\hline Zone-5 & 442.68 & 359.94 & 18.6 \\
\hline
\end{tabular}

TABLE 4 COMPARING DISPLACEMENTS BETWEEN MODEL-1 AND MODEL-4

\begin{tabular}{|c|c|c|c|}
\hline 8 STOREY & $\begin{array}{c}\text { (MODEL-1) } \\
\text { DISPLACEMENT }(\mathrm{mm})\end{array}$ & $\begin{array}{c}\text { (MODEL-4) } \\
\text { DISPLACEMENT (mm ) }\end{array}$ & $\begin{array}{c}\text { \% reduction in } \\
\text { Displacement }\end{array}$ \\
\hline Zone-2 & 130.24 & 96.51 & 25.8 \\
\hline Zone-3 & 203.11 & 151.88 & 25.2 \\
\hline Zone-4 & 301.37 & 226.6 & 24.8 \\
\hline Zone-5 & 442.68 & 334.23 & 24.4 \\
\hline
\end{tabular}

TABLE 5 DISPLACEMENT REDUCTION IN EACH FRAME

\begin{tabular}{|c|c|c|}
\hline TYPE & $\begin{array}{c}\text { DISPLACEMENT } \\
(\mathrm{mm})\end{array}$ & $\begin{array}{c}\text { \% reduction in Displacement } \\
\text { for each Frame }\end{array}$ \\
\hline $\begin{array}{c}\text { RCC FRAME WITHOUT SHEAR } \\
\text { WALL (MODEL-1) }\end{array}$ & 329 & 0 \\
\hline $\begin{array}{c}\text { RCC FRAME WITH SHEAR } \\
\text { WALL POSITION-1(MODEL-2) }\end{array}$ & 251 & 24 \\
\hline $\begin{array}{c}\text { RCC FRAME WITH SHEAR } \\
\text { WALL POSITION-2(MODEL-3) }\end{array}$ & 245 & 26.7 \\
\hline $\begin{array}{c}\text { RCC FRAME WITH SHEAR } \\
\text { WALL POSITION-3(MODEL-4) }\end{array}$ & 241 & \\
\hline
\end{tabular}


TABLE 6 BASE FORCE INCREASE IN EACH FRAME

\begin{tabular}{|l|c|c|}
\hline \multicolumn{1}{|c|}{ TYPE } & BASE FORCE(KN) & \% increase in base force \\
\hline $\begin{array}{l}\text { RCC FRAME WITHOUT SHEAR } \\
\text { WALL (MODEL-1) }\end{array}$ & 1790 & 0 \\
\hline $\begin{array}{l}\text { RCC FRAME WITH SHEAR WALL } \\
\text { POSITION-1(MODEL-2) }\end{array}$ & 1985 & 9.82 \\
\hline $\begin{array}{l}\text { RCC FRAME WITH SHEAR WALL } \\
\text { POSITION-2(MODEL-3) }\end{array}$ & 1935 & 7.49 \\
\hline $\begin{array}{l}\text { RCC FRAME WITH SHEAR WALL } \\
\text { POSITION-3(MODEL-4) }\end{array}$ & 1942 & 7.82 \\
\hline
\end{tabular}

VIII DISCUSSION OF RESULTS

From the static direct examination it watched that the greatest relocation of frame (model-2) is decreased 8.5\% in Zone-II, 9.1\% in Zone-III, 9.5\% in Zone-IV, 9.7\% in Zone-V as contrasting and RCC plane edge.

From the static direct examination it watched that the greatest relocation of frame (model-3) is decreased $17.5 \%$ in Zone-II, 18.1\% in Zone-III, 15.5\% in Zone-IV, 18.6\% in Zone-V as contrasting and RCC plane edge.

From the static straight investigation it watched that the greatest dislodging of frame (model-4) is decreased 25.8\% in Zone-II, 25.2\% in Zone-III, $24.8 \%$ in Zone-IV, 24.4\%in Zone-V as contrasting and RCC plane edge. So shear divider in position-3 is more effective than the other casing.

It can be watched that from static nonlinear examination the most extreme displacement,RCC plane edge (Model-1) that can withstand up as far as possible is $329 \mathrm{~mm}$ and the corresponding base response is $1790 \mathrm{KN}$.

From the push-over bend, it is noticed that the greatest uprooting for the shear Wall RCC outline (Model-2) can withstand up to as far as possible $251 \mathrm{~mm}$ and reduction up to $24 \%$ in relocation when the shear divider is given atposition-1.

From the push-over bend, it is noticed that the most extreme removal for the Shear Wall RCC outline (Model-3) can withstand up to as far as possible $245 \mathrm{~mm}$ and reduction up to $25.5 \%$ in relocation when the shear divider is given at position-2.

From the push-over bend, it is noticed that the greatest dislodging for the Shear Wall RCC outline (Model-4) can withstand up to as far as possible $241 \mathrm{~mm}$ and reduction up to $26.7 \%$ in uprooting when the shear divider is given at position-3.

\section{CONCLUSIONS}

- From the pushover curves, it can be concluded that RCC Frames with Shear Walls are able to resist about 9.82\% more base-shear than that of normal RCC Frames considering in this study.

- From the pushover curves, it can be concluded that RCC Frames with Shear Walls are able to reduce about 26.7\% displacement than that of normal RCC Frames considered in this study.

- From the static linear analysis the maximum displacement of frame (model-4) is reduced by $25.8 \%$ in ZoneII, 25.2\% in Zone-III, 24.8 in Zone-IV, 24.4\% in Zone-V as compared to RCC plane frame. So shear wall in position-3 is more effective than the other frame in case of displacement.

- It can be concluded that shear wall at adequate locations is more significant in case of base shear and displacement.

- It is observed that for the 8 storey building providing shear wall at mid span of the building in the long span direction is economical as compared with other models.

- Changing the position of shear wall will affect the attraction of forces, so that wall must be in proper position.

- It is also observed that lateral displacement is reduced when the shear walls are added at the appropriate locations of frames.

- It can be concluded that shear wall with various positioning in frame is effective in different models.

- Planning in proper position of shear wall in building rises to control the lateral forces.

- The hinge status of the four models at the performance point provided almost the same pattern.

- Different levels of elastic zone are represented with respective colour mentioned. The Immediate Occupancy to Life Safety zone (IO- LS) is mentioned in dark blue in colour, Life Safety to Collapse Prevention zone (LS-CP) is mentioned in light blue in colour and Collapse Prevention zone is mentioned in green colour.

- The results indicate better resistance to lateral load in the presence of shear wall. 


\section{REFERENCES}

[1] Karim Tarbali, Kazem Shakeri, Story shear and torsional moment-based pushover procedure for asymmetric-plan buildings using an adaptive capacity spectrum method, Engineering Structures 79 (2014) 32-44

[2] Kazem Shakeri, Mohsen A. Shayanfar, Toshimi Kabeyasawa, A story shear-based adaptive pushover procedure for estimating seismic demands of buildings, Engineering Structures 32 (2010) 174-183

[3] Shaik Kamal Mohammed Azam, Vinod Hosur, Seismic Performance Evaluation of Multistoried RCframed buildings with Shear wall, International Journal of Scientific \& Engineering Research Volume 4, Issue 1, January-2013.

[4] Mangulkar Madhuri N. Review On Shear Wall For Soft Story High-RiseBuildings. International Journal of Engineering and Advanced Technology(IJEAT), ISSN: 2249 - 8958, Volume-1, Issue-6, August 2012.

[5] 5.Y.M.Fahjan 2010 Nonlinear Analysis Methods for Reinforced Concrete Buildings with Shear walls $14^{\text {th }}$ ECEE 2010 Conference

[6] Anil K. Chopra, Rakesh K. Goel, A model pushover analysis procedure to estimate seismic demands fr unsmetric-plan buildings; Earthquake Engineering and structural dynamics 2004, 33: 903-927.

[7] Anshuman.S. Solution Of Shear Wall Location In Multi-Storey Building.International Journal of Civil and Structural Engineering, ISSN 0976 - 4399, Volume 2, No 2, 2011.

[8] O. Esmaili S Study Of Structural Rc Shear Wall System In A 56-Story RcTall Building. The $14^{\text {th }}$ World Conference on Earthquake Engineering, Oct2008, Beijing, China.

[9] Y.M. Fahjan. Nonlinear Analysis Methods For Reinforced Concrete BuildingsWith Shear Walls. Gebze Institute of Technology, 41400 Gebze, Kocaeli,Turke.

[10] A. Kadid, Pushover Analysis Of Reinforced Concrete Frame Structures.Asian Journal Of Civil Engineering (Building And Housing) Vol. 9, No. 1 (2008).

[11] Anil K. Chopra A Modal Pushover Analysis Procedure For EstimatingSeismic Demands For Buildings. EARTHQUAKE ENGINEERING ANDSTRUCTURAL DYNAMICS Earthquake Engineering Structural. Dynamics 2002.

[12] Sun-Pil Kim(2008), “An Alternative Pushover Analysis Procedure ToEstimate Seismic Displacement Demands”. Engineering Structures 30(2008).

\section{AUTHORS PROFILE}

Dr . Vaishali G Ghorpade is currently Professor in the Department Civil Engineering Department at JNTUA College of Engineering Anantapur,India. Her areas of interests are High Performance concrete, Fibre Reinforced Concrete, Glass Fibre Reinforcement Concrete, SIFCON, Low Cost Housing materials and techniques and Artificial Neural Networks

Dr .H. Sudarsana Rao is a senior Professor of Civil Engineering Department at JNTUA College of Engineering Anantapur,India. He is presently working as Director (ICS) at JNTU Anantapur. His research interests are Finite element analysis, seismic analysis ,Application of Artificial Neural Networks, Concrete Composites etc,.

O Ravi pursuing M.Tech in Structural Engineering from JNTU, Anantapur , India 